\title{
ALGORITMA K-MEANS CLUSTERING UNTUK MENENTUKAN STRATEGI PEMASARAN DI CV. INTEGREET KONSTRUKSI
}

\author{
Ali Akbar Rismayadi', Novia Nur Fatonah², Erfian Junianto ${ }^{3}$ \\ 1 Universitas Adhirajasa Reswara Sanjaya \\ e-mail: ali@ars.ac.id \\ ${ }^{2}$ Universitas Adhirajasa Reswara Sanjaya \\ e-mail: fatonahnovia@gmail.com \\ 3Universitas Adhirajasa Reswara Sanjaya \\ e-mail: erfian.ejn@ars.ac.id
}

\begin{abstract}
Abstrak
Semakin ketatnya persaingan bisnis, menuntut setiap perusahan untuk bekerja semaksimal mungkin agar dapat tetap unggul dalam persaingan. Salah satu caranya adalah dengan menentukan strategi pemasaran yang paling tepat guna menarik konsumen yang lebih banyak. CV.Integreet Konstruksi merupakan sebuah perusahaan jasa yang bergerak di bidang konstruksi, untuk sebuah perusahaan yang cukup besar perusahaan ini masih sering kesulitan dalam menentukan strategi pesaran seperti apa yang paling tepat, hal tersebut berdampak pada jumlah penjualan yang menurun setiap bulannya. Informasi dari data penjualan sebenarnya dapat di olah untuk dijadikan dasar dalam penentuan strategi pemasaran yang tepat. Diperlukan suatu teknik atau perangkat untuk membantu mentransformasikan data tersebut menjadi informasi berguna yaitu dengan penerapan data mining. Salah satu metode dari data mining yang dapat digunakan adalah metode Clustering, di mana metode ini akan mengidentifikasi objek yang memiliki kesamaan karakteristik tertentu. Algoritma yang digunakan untuk pembentukan cluster adalah algoritma K-Means. Dalam penelitian ini data yang digunakan adalah data penjualan dari bulan Agustus-November yang terdiri dari 212 sampel data. Cluster yang terbentuk berjumlah tiga cluster, dengan cluster pertama berjumlah 103 data, cluster dua berjumlah 58 data, dan cluster ke tiga berjumlah 51 data. Hasil dari penelitian ini dapat digunakan sebagai bahan dasar dalam penentuan strategi pemasaran yang paling tepat.
\end{abstract}

Kata Kunci: Clustering, Data Mining, Data Penjualan, K-Means, Strategi Marketing

\begin{abstract}
The increasingly fierce business competition, requires each company to work as much as possible in order to excel in competition. One way is to determine the most appropriate marketing strategy to attract more consumers. CV.Integreet Construction is a service company engaged in construction, for a fairly large company this company is still often difficult in determining the magnification strategy as what is most appropriate, it has an impact on the number of sales that decline each month. Information from sales data can actually be used as a basis for determining the right marketing strategy. A technique or tool is needed to help transform the data into useful information by applying data mining. One method of data mining that can be used is the Clustering method, where this method will identify objects that have certain characteristics in common. The algorithm used for cluster formation is the K-Means algorithm. In this study the data used are sales data from August to November consisting of 212 data samples. Clusters formed amounted to three clusters, with the first cluster totaling 103 data, cluster two totaling 58 data, and the third cluster totaling 51 data. The results of this study can be used as a basic ingredient in determining the right marketing strategy.
\end{abstract}

Keywords: : Clustering, Data Mining, Data Penjualan, K-Means, Strategi Marketing. 


\section{Pendahuluan}

Persaingan bisnis yang kian meningkat saat ini menuntut setiap perusahaan atau organisasi untuk memanfaatkan kemampuannya semaksimal mungkin, agar dapat unggul dalam persaingan (Wulandari, 2014), strategi pemasaran merupakan salah satu bagian yang sangat penting bagi setiap perusahaan dan sesuatu yang penting umumnya tidak dapat dirumuskan dan dilaksanakan dengan mudah, dibutuhkan serangkaian analisis yang mendalam untuk mengurangi ketidakpastian atau resiko yang mungkin dihadapi dari masing-masing strategi yang akan diterapkan (Basalamah et al., 2018). Oleh sebab itu diperlukan suatu teknik atau perangkat untuk membantu mentransformasikan data dengan jumlah yang besar tersebut menjadi informasi berguna yaitu dengan penerapan data mining (Nurjoko \& Darmawan, 2015).

Data mining merupakan ekstrasi pola yang mengambil data dalam jumlah besar, dan suatu strategi dikatakan menarik apabila strategi tersebut tidak simple, implisit, dan tidak diketahui sebelumnya, serta berguna, strategi yang hasilkan haruslah mudah dipahami, serta dapa di pergunakan untuk data yang akan diprediksi dengan derajat kepastian tertentu (Marsono, 2019). Data mining dapat meramalkan tren atau hal yang lagi berkembang saat ini serta dapat menjelaskan sifat-sifat perilaku bisnis yang sangat berguna untuk mendukung pengambilan keputusan penting. Data mini juga dapat di jadikan sebagai alternatif pendukung untuk pengambilan keputusan dalam membuat bussines solution serta dengan dukungan infrastruktur dibidang teknologi informasi hal ini dapat mendorong lahirnya suatu teknologi data mining (Anisya, 2020).

Salah satu metode dari data mining yang dapat digunakan adalah metode pengelompokan (Clustering), di mana metode ini akan mengidentifikasi objek yang memiliki kesamaan karakteristik tertentu, kemudian menggunakan karakteristik tersebut sebagai pembanding atau acuan untuk menentukan strategi pemasarannya (Bahar et al., 2016). K-means clustering merupakan salah satu metode data clustering yang akan mempartisi data yang ada ke dalam bentuk cluster atau kelompok, sehingga data yang memiliki karakteristik yang sama akan dikelompokkan ke dalam satu cluster yang sama dan data yang mempunyai karakteristik yang berbeda dikelompokkan ke dalam kelompok yang lain (Metisen \& Sari, 2015). Data yang diproses dengan algoritma $K$-Means Clustering akan menciptakan suatu ilmu baru yang bersumber dari data lama, hasil yang diperoleh dari pemprosesan data tersebut bisa digunakan untuk menentukan keputusan di masa (Alkhairi \& Windarto, 2019).

CV.Integreet Konstruksi merupakan sebuah perusahaan jasa yang bergerak di bidang konstruksi bangunan. Untuk sebuah perusahaan yang cukup besar CV.Integreet Konstruksi masih sering kesulitan dalam menentukan strategi pesaran yang paling tepat agar dapat menarik konsumen yang lebih banyak, hal tersebut berdampak pada jumlah penjualan yang menurun setiap bulannya, seperti yang bisa dilihat pada gambar 1, grafik tersebut menunjukan jumlah penjualan menurun sejak bulan Me 2019.

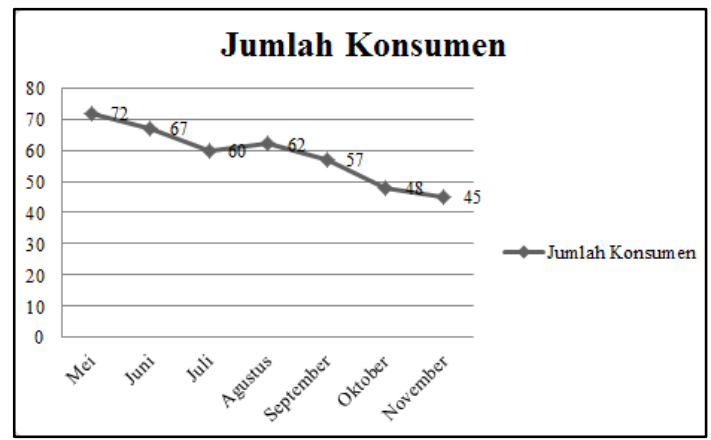

Gambar 1. Grafik Data Penjualan

Penelitian sebelumnya yang menitik beratkan pada penggunaan algoritma Kmeans adalah penelitian dari (Mulaki et al., 2018), yang membahas Analisis data mahasiswa menggunakan algoritma kmeans clustering sebagai dasar pelaksana promosi yang dapat menghasilkan pengelompokan data berdasarkan berdasarkan asal provinsi, prodi dan asal sekolah. Sehingga bisa di dapatkan jumlah mahasiswa yang besar pada suatu prodi serta asal sekolah yang dominan pada suatu prodi sebagai bagian penting dalam penerapan strategi promosi yang akan di jalankan.

Penelitian lainnya yang dilakukan oleh (Nduru et al., 2018) mengenai implementasi algoritma K-Means Clustering untuk menentukan strategi pemasaran menunjukan bahwa algoritma K-means 
clustering dapat digunakan sebagai dasar penentuan strategi pemasaran yang tepat untuk menentukan jumlah objek berdasarkan kriteria kriteria yang telah di tentukan.

\section{Metode Penelitian}

Pada bagian ini, akan dijelaskan gambaran mengenai metodologi penelitian secara keseluruhan yang didasarkan pada CRISP-DM. Berikut adalah tahapan yang dilakukan dalam penelitian ini seperti yang terlihat pada gambar 2 .

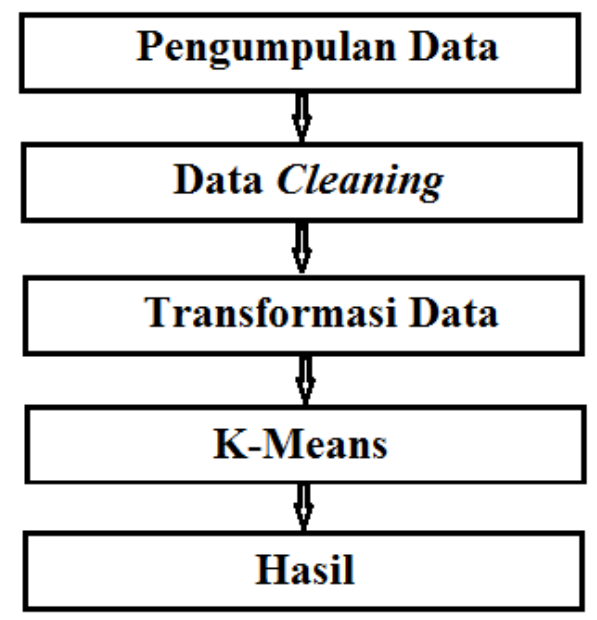

Gambar 2. Tahapan Penelitian

Tahap pertama yang peneliti lakukan adalah mengumpulkan data, data yang digunakan dalam penelitian ini adalah data private yang diambil langsung dari hasil riset di CV.Integreet Konstruksi. Penelitian ini menggunakan dataset data penjualan di CV.Integreet Konstruksi pada bulan 08usNovember 2019 yang terdiri dari 212 sampel data, dengan atribut nama konsumen, lokasi proyek, jenis pekerjaan dan sumbernya.

Tahap berikutnya adalah memastikan data penjualan yang dipilih telah layak untuk dilakukan proses pengolahan. Pada tahap ini dilakukan pemilihan atribut data yang akan digunakan dalam penelitian.

Tabel 1. Data Penjualan Bulan AgustusNovember 2019

\begin{tabular}{|c|c|c|c|c|c|}
\hline \multicolumn{6}{|c|}{ DATA ORDER BULAN AGUSTUS-NOVEMBER 2019} \\
\hline $\begin{array}{l}\mathbf{N} \\
\mathbf{0}\end{array}$ & $\begin{array}{c}\mathrm{Tg} \\
\mathrm{I}\end{array}$ & $\begin{array}{c}\text { Nam } \\
\text { a }\end{array}$ & Lokasi & $\begin{array}{c}\text { Jenis } \\
\text { Pekerjaan }\end{array}$ & Sumber \\
\hline 1 & $\begin{array}{l}01- \\
08 \\
\end{array}$ & Pipit & $\begin{array}{c}\text { Kab. } \\
\text { Bandung }\end{array}$ & $\begin{array}{c}\text { Konstruksi } \\
\text { WF }\end{array}$ & OLX \\
\hline 2 & $\begin{array}{l}01- \\
08 \\
\end{array}$ & Fani & $\begin{array}{c}\text { Kab. } \\
\text { Bandung }\end{array}$ & Plafon & OLX \\
\hline 3 & $\begin{array}{l}01- \\
08 \\
\end{array}$ & Lily & $\begin{array}{c}\text { Kota } \\
\text { Bandung }\end{array}$ & $\begin{array}{c}\text { Angkutan } \\
\text { Barang }\end{array}$ & $\begin{array}{c}\text { Faceboo } \\
\text { k Ads }\end{array}$ \\
\hline
\end{tabular}

\begin{tabular}{|c|c|c|c|c|c|}
\hline 4 & $\begin{array}{c}01- \\
08\end{array}$ & Amel & Cimahi & COR Beton & $\begin{array}{c}\text { Tokopedi } \\
\text { a }\end{array}$ \\
\hline 5 & $\begin{array}{c}02- \\
08\end{array}$ & Linda & $\begin{array}{c}\text { Sumedan } \\
\mathrm{g}\end{array}$ & $\begin{array}{c}\text { Kusen } \\
\text { Alumunium }\end{array}$ & $\begin{array}{c}\text { Faceboo } \\
\text { k Ads }\end{array}$ \\
\hline 6 & $\begin{array}{l}03- \\
08\end{array}$ & Sri & Bogor & $\begin{array}{c}\text { Angkutan } \\
\text { Barang }\end{array}$ & $\begin{array}{l}\text { Marketpl } \\
\text { ace }\end{array}$ \\
\hline 7 & $\begin{array}{l}04- \\
08\end{array}$ & Arifin & $\begin{array}{c}\text { Kota } \\
\text { Bandung }\end{array}$ & Kanopi & $\begin{array}{l}\text { Marketpl } \\
\text { ace }\end{array}$ \\
\hline 8 & $\begin{array}{l}05- \\
08\end{array}$ & Farid & Depok & Pagar & $\begin{array}{c}\text { Tokopedi } \\
\text { a }\end{array}$ \\
\hline 9 & $\begin{array}{l}05- \\
08\end{array}$ & Ardhi & $\begin{array}{c}\text { Bandung } \\
\text { Barat }\end{array}$ & Plafon & $\begin{array}{c}\text { Marketpl } \\
\text { ace }\end{array}$ \\
\hline $\begin{array}{l}1 \\
0\end{array}$ & $\begin{array}{l}05- \\
08 \\
\end{array}$ & Endy & Cimahi & $\begin{array}{c}\text { Atap Baja } \\
\text { Ringan }\end{array}$ & $\begin{array}{c}\text { Instagra } \\
\mathrm{m}\end{array}$ \\
\hline .. & $\cdots$ & ........ & …......... & ………... & …......... \\
\hline $\begin{array}{l}2 \\
1 \\
1\end{array}$ & $\begin{array}{l}29- \\
11\end{array}$ & $\begin{array}{l}\text { Bagu } \\
\mathrm{s}\end{array}$ & $\begin{array}{c}\text { Kab. } \\
\text { Bandung }\end{array}$ & Plafon & $\begin{array}{c}\text { Tokopedi } \\
\text { a }\end{array}$ \\
\hline $\begin{array}{l}2 \\
1 \\
2\end{array}$ & $\begin{array}{c}30- \\
11\end{array}$ & Uus & $\begin{array}{c}\text { Kab. } \\
\text { Bandung }\end{array}$ & $\begin{array}{l}\text { Renovasi } \\
\text { Rumah }\end{array}$ & $\begin{array}{c}\text { Instagra } \\
\text { m }\end{array}$ \\
\hline
\end{tabular}

Selanjutnya adalah mentransformasi data, data yang berjenis nominal seperti jenis pekerjaan dan sumber harus dilakukan proses inisialisasi data terlebih dahulu ke dalam bentuk angka atau numerical. Untuk melakukan inisialisasi dapat dilakukan dengan cara pengurutan angka berdasarkan frekuensinya.

Tabel 2. Tabel Inisialisasi Lokasi

\begin{tabular}{|c|c|c|c|}
\hline No & Lokasi & Frekuensi & Inisialisai \\
\hline 1 & Kota Bandung & 44 & 1 \\
\hline 2 & Kab. Bandung & 37 & 2 \\
\hline 3 & Cimahi & 34 & 3 \\
\hline 4 & Bandung Barat & 26 & 4 \\
\hline 5 & Sumedang & 15 & 5 \\
\hline 6 & Jakarta & 14 & 6 \\
\hline 7 & Tangerang & 12 & 7 \\
\hline 8 & Bogor & 11 & 8 \\
\hline 9 & Bekasi & 7 & 9 \\
\hline 10 & Depok & 6 & 10 \\
\hline 11 & Garut & 4 & 11 \\
\hline 12 & Lain-lain & 2 & 12 \\
\hline
\end{tabular}

Pada tabel 2. Berisi penjelasan mengenai inisialisasi lokasi

Tabel 3. Tabel Inisialisai Jenis Pekerjaan

\begin{tabular}{|c|c|c|c|}
\hline No & Jenis Pekerjaan & Frekuensi & Inisialisai \\
\hline 1 & Angkutan Barang & 39 & 1 \\
\hline 2 & Kanopi & 31 & 2 \\
\hline 3 & Kusen Alumunium & 26 & 3 \\
\hline 4 & Atap Baja Ringan & 23 & 4 \\
\hline
\end{tabular}




\begin{tabular}{|c|c|c|c|}
5 & Plafon & 22 & 5 \\
\hline 6 & Partisi & 17 & 6 \\
\hline 7 & Konstruksi WF & 14 & 7 \\
\hline 8 & Renovasi Rumah & 12 & 8 \\
\hline 9 & COR Beton & 11 & 9 \\
\hline 10 & Instalasi Listrik & 9 & 10 \\
\hline 11 & Pagar & 8 & 11 \\
\hline
\end{tabular}

Pada tabel 3. Berisi data inisialisasi jenis pekerjaan.

Tabel 4. Tabel Sumber

\begin{tabular}{|c|l|c|c|}
\hline No & \multicolumn{1}{|c|}{ Sumber } & Frekuensi & Inisialisasi \\
\hline 1 & OLX & 81 & 1 \\
\hline 2 & Facebook Ads & 40 & 2 \\
\hline 3 & Tokopedia & 24 & 3 \\
\hline 4 & Marketplace & 20 & 4 \\
\hline 5 & Instagram & 14 & 5 \\
\hline 6 & Sejasa & 13 & 6 \\
\hline 7 & Website & 8 & 7 \\
\hline 8 & Tokoreklame & 6 & 8 \\
\hline 9 & Kerabat & 4 & 9 \\
\hline 10 & Youtube & 2 & 10 \\
\hline
\end{tabular}

Pada tabel 4. Dijelaksan mengenai sumber seperti OLX, Facebpook Ads, dan lainnya.

Tabel 5. Contoh Dataset yang Sudah Dilakuakan Inisialisasi

\begin{tabular}{|c|c|c|c|c|c|}
\hline \multicolumn{6}{|c|}{ DATA ORDER BULAN AGUSTUS-NOVEMBER 2019} \\
\hline No & Tgl & Nama & Lokasi & $\begin{array}{c}\text { Jenis } \\
\text { Pekerjaan }\end{array}$ & Sumber \\
\hline 1 & $\begin{array}{c}01- \\
08\end{array}$ & Pipit & 2 & 7 & 1 \\
\hline 2 & $\begin{array}{c}01- \\
08\end{array}$ & Fani & 2 & 5 & 1 \\
\hline 3 & $\begin{array}{c}01- \\
08\end{array}$ & Lily & 1 & 1 & 2 \\
\hline 4 & $\begin{array}{c}01- \\
08\end{array}$ & Amel & 3 & 9 & 3 \\
\hline 5 & $\begin{array}{c}02- \\
08\end{array}$ & Linda & 12 & 5 & 1 \\
\hline 6 & $\begin{array}{c}03- \\
08\end{array}$ & Sri & 8 & 1 & 4 \\
\hline 7 & $\begin{array}{c}04- \\
08\end{array}$ & Arifin & 1 & 2 & 4 \\
\hline 8 & $\begin{array}{c}05- \\
08\end{array}$ & Farid & 10 & 11 & 3 \\
\hline 9 & $\begin{array}{c}05- \\
08\end{array}$ & Ardhi & 4 & 5 & 4 \\
\hline 10 & $\begin{array}{c}05- \\
08\end{array}$ & Endy & 3 & 4 & 5 \\
\hline$\ldots$ & $\ldots$. & $\ldots \ldots$ & $\ldots \ldots$ & $\ldots \ldots \ldots$ & $\ldots$ \\
\hline 211 & $\begin{array}{c}29- \\
11\end{array}$ & Bagus & 2 & 5 & 3 \\
\hline
\end{tabular}

\begin{tabular}{|l|r|l|l|l|l|}
212 & $30-$ & Uus & 2 & 8 & 5 \\
\hline
\end{tabular}

Tahap selanjutnya adalah mengolah data menggunakan algoritma k-means clustering sehingga dapat menghasilkan informasi yang bermanfaat dan dapat menjadi pertimbangan dalam hal pengambilan keputusan. Penelitian ini juga menggunakan perangkat lunak rapidminer versi 9.0. sebagai software pendukung.

\section{Hasil dan Pembahasan}

Untuk menentukan banyaknya cluster $\mathrm{k}$ dapat dilakukan dengan beberapa pertimbangan seperti pertimbangan teoritis dan konseptual yang mungkin diusulkan untuk menentukan berapa banyak cluster. Penetapan jumlah cluster $\mathrm{k}$ pada penelitian ini yaitu berjumlah 3 cluster.

Tabel 6. Titik Awal Cluster

\begin{tabular}{|c|c|c|c|}
\hline $\begin{array}{c}\text { Titik Pusat } \\
\text { Awal }\end{array}$ & Lokasi & $\begin{array}{c}\text { Jenis } \\
\text { Pekerjaan }\end{array}$ & Sumber \\
\hline Cluster 1 & 8 & 1 & 4 \\
\hline Cluster 2 & 10 & 11 & 3 \\
\hline Cluster 3 & 11 & 6 & 2 \\
\hline
\end{tabular}

Hitung jarak ke pusat cluster antara objek ke centroid dengan perhitungan jarak Euclidean. Persamaan yang digunakan adalah :

$$
(p, q)=\sqrt{(\mathrm{p} 1-\mathrm{q} 1)^{2}+(\mathrm{p} 2-\mathrm{q} 2)^{2}+(\mathrm{p} 3-\mathrm{q} 3)^{2}}
$$

Persamaan ini digunakan karena atribut yang digunakan berjumlah 3 . Sebagai contoh, akan dihitung jarak dari lima data penualan teratas ke pusat cluster awal dengan persamaan :

$$
\begin{aligned}
& =\sqrt{(2-8)^{2}+(7-1)^{2}+(1-4)^{2}} \\
& =\sqrt{(-6)^{2}+(6)^{2}+(-3)^{2}} \\
& =\sqrt{36+36+9} \\
& =\sqrt{81} \\
& =9
\end{aligned}
$$

Dari hasil perhitungan di atas di dapatkan hasil bahwa jarak data penjualan pertama dengan cluster pertama adalah 9.

$$
\begin{aligned}
& =\sqrt{(2-10)^{2}+(7-11)^{2}+(1-3)^{2}} \\
& =\sqrt{(-8)^{2}+(-4)^{2}+(-2)^{2}} \\
& =\sqrt{64+16+4} \\
& =\sqrt{84} \\
& =9,165
\end{aligned}
$$


Dari hasil perhitungan di atas di dapatkan hasil bahwa jarak data penjualan pertama dengan cluster kedua adalah 9,165.

$$
\begin{aligned}
(1,3) & =\sqrt{(2-11)^{2}+(7-6)^{2}+(1-2)^{2}} \\
& =\sqrt{(-9)^{2}+(1)^{2}+(-1)^{2}} \\
& =\sqrt{81+1+1} \\
& =\sqrt{83} \\
& =9,110
\end{aligned}
$$

Dari hasil perhitungan di atas di dapatkan hasil bahwa jarak data penjualan pertama dengan cluster ketiga adalah 9,110.

\begin{tabular}{|c|c|c|c|c|c|c|}
\hline \multirow{2}{*}{$\begin{array}{l}\text { Lok } \\
\text { asi }\end{array}$} & \multirow{2}{*}{$\begin{array}{c}\text { Jenis } \\
\text { Peker } \\
\text { jaan }\end{array}$} & \multirow{2}{*}{$\begin{array}{c}\text { Su } \\
\text { mb } \\
\text { er }\end{array}$} & \multicolumn{3}{|c|}{ Jarak } & \multirow{2}{*}{$\begin{array}{l}\text { Clu } \\
\text { ster }\end{array}$} \\
\hline & & & C1 & $\mathrm{C} 2$ & C3 & \\
\hline 2 & 7 & 1 & 9.000 & 9.165 & 9.110 & 1 \\
\hline 2 & 5 & 1 & 7.810 & 10.198 & 9.110 & 1 \\
\hline 1 & 1 & 2 & 7.280 & 13.491 & 11.180 & 1 \\
\hline 3 & 9 & 3 & 9.487 & 7.280 & 8.602 & 2 \\
\hline 12 & 5 & 1 & 6.403 & 6.633 & 1.732 & 3 \\
\hline 8 & 1 & 4 & 0.000 & 10.247 & 6.164 & 1 \\
\hline 1 & 2 & 4 & 7.071 & 12.767 & 10.954 & 1 \\
\hline 10 & 11 & 3 & $\begin{array}{c}10.24 \\
7\end{array}$ & 0.000 & 5.196 & 2 \\
\hline 4 & 5 & 4 & 5.657 & 8.544 & 7.348 & 1 \\
\hline 3 & 4 & 5 & 5.916 & 10.100 & 8.775 & 1 \\
\hline
\end{tabular}

Berikut ini table hasil perhitungan data ke tiap cluster :

Tabel 7. Contoh Hasil Perhitungan Data Ke Tiap Cluster

Berdasarkan hasil perhitungan tersebut dapat disimpulkan bahwa jarak data penjualan pertama yang paling dekat adalah 9, sehingga data penjualan pertama dimasukan ke dalam cluster 1.

Setelah itu kelompokan data ke dalam cluster dengan jarak terdekat (minimum).

Tabel 8. Cluster Dengan Centroid Awal

\begin{tabular}{|c|c|c|c|}
\hline No & Cluster 1 & Cluster 2 & Cluster 3 \\
\hline 1 & 1 & 0 & 0 \\
\hline 2 & 1 & 0 & 0 \\
\hline 3 & 1 & 0 & 0 \\
\hline 4 & 0 & 1 & 0 \\
\hline 5 & 0 & 0 & 1 \\
\hline 6 & 1 & 0 & 0 \\
\hline
\end{tabular}

\begin{tabular}{|c|c|c|c|}
7 & 1 & 0 & 0 \\
\hline 8 & 0 & 1 & 0 \\
\hline 9 & 1 & 0 & 0 \\
\hline 10 & 1 & 0 & 0 \\
\hline
\end{tabular}

Setelah semua data ditempatkan ke dalam cluster yang terdekat, kemudian hitung kembali pusat cluster yang baru berdasarkan rata-rata anggota yang ada pada cluster tersebut.

$\mathrm{Ci} \quad=\left(\frac{\Sigma \text { Jumlah Jenis Pekerjaan C1 }}{\text { Jumlah Data Anggota C1 }} ;\right.$

$\Sigma$ Jumlah Sumber C2 $; \sum$ Jumlah Pembayaran C3

Contoh perhitungan pada cluster 1 adala sebagai berikut :

$$
\frac{21}{7} ; \frac{25}{7} ; \frac{21}{7}
$$

Jadi, hasil centroid baru cluster 1 adalah ( 3 ; $3,5 ; 3)$.

Contoh perhitungan pada cluster 2 adalah sebagai berikut :

$$
\frac{13}{2} ; \frac{20}{2} ; \frac{6}{2}
$$

Jadi, hasil centroid baru cluster 2 adalah $(6,5$ ; $10 ; 3)$.

Contoh perhitungan pada cluster 3 adalah sebagai berikut :

$$
\frac{12}{1} ; \frac{5}{1} ; \frac{1}{1}
$$

Jadi, hasil centroid baru cluster 3 adalah (12 ;5;1).

Tabel 9. Centroid Baru

\begin{tabular}{|c|c|c|c|}
\hline & Lokasi & $\begin{array}{c}\text { Jenis } \\
\text { Pekerjaan }\end{array}$ & Sumber \\
\hline Cluster 1 & 3 & 3,5 & 3 \\
\hline Cluster 2 & 6,5 & 10 & 3 \\
\hline Cluster 3 & 12 & 5 & 1 \\
\hline
\end{tabular}

Setelah didapatkan titik pusat yang baru dari setiap cluster, lakukan kembali dari langkah diatas hingga titik pusat dari setiap cluster tidak berubah lagi dan tidak ada lagi data yang berpindah dari satu cluster ke cluster yang lain. 
Untuk memastikan hasil perhitungan manual di Microsoft excel dan perhitungan software rapidminer 9.0 tidak jauh berbeda maka dibuat perbandingan seperti berikut.

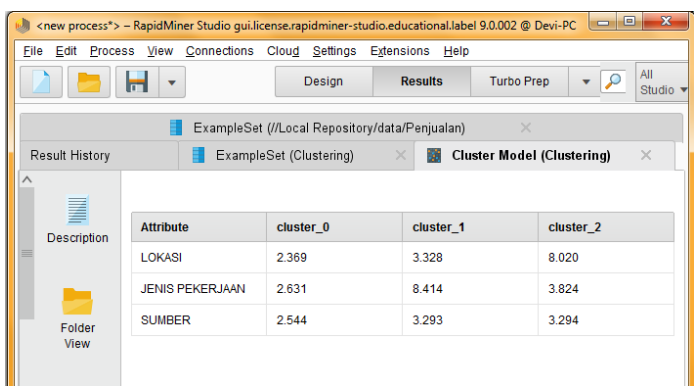

Gambar 3. Hasil Perhitungan Pada Aplikasi Rapidminer

Sumber : Aplikasi Rapidminer V.9.0.

Tabel 10. Hasil Perhitungan Pada Microsoft Excel

\begin{tabular}{|l|c|c|c|}
\hline & Lokasi & $\begin{array}{c}\text { Jenis } \\
\text { Pekerjaan }\end{array}$ & Sumber \\
\hline Cluster 1 & 2,30 & 3,59 & 2,40 \\
\hline Cluster 2 & 3,56 & 8,96 & 5,00 \\
\hline Cluster 3 & 7,80 & 5,41 & 3,12 \\
\hline
\end{tabular}

Berdasarkan hasil dari perhitungan, 212 data penjualan dibagi ke dalam 3 cluster berdasarkan lokasi, jenis pekerjaan dan sumbernya. Cluster 1 terdiri dari 103 data. Cluster 2 terdiri dari 58 data. Cluster 3 terdiri dari 51 data. Cluster 1 adalah kelompok dengan rata-rata penjualan paling tinggi dan paling tepat untuk dijadikan sebagai dasar dalam penentuan strategi pemasaran, dengan lokasi di Kabupaten bandung, jenis pekerjaannya kanopi dan sumbernya dari fitur facebook ads. Cluster 2 adalah kelompok dengan rata-rata penjualan paling rendah, sehingga kurang tepat untuk dijadikan dasar dalam penentuan strategi penjualan, dengan lokasi di Cimahi, jenis pekerjaannya renovasi rumah dan sumbernya dari tokopedia. Cluster 3 adalah klompok data yang berada di tengah-tengah dan masih bisa dipertimbangkan untuk dijadikan dasar penentuan strategi pemasaran, dengan lokasi di Bogor, jenis pekerjaannya Kusen Alumunium dan sumbernya dari Tokopedia.

Hasil dari penelitian ini dapat membantu pihak perusahaan untuk mengambil keputusan dalam memilih strategi pemasaran yang tepat agar bisa menarik konsumen yang lebih banyak.

\section{Kesimpulan}

Untuk mencegah kesalahan perusahaan dalam menentukan strategi pemasaran yang tepat guna meningkatkan jumlah pendapatan, maka dapat dilakukan pencegahan dengan menggunakan teknik data mining sehingga pihak perusahaan dapat menentukan keputusan secara cepat dan tepat.

Berdasarkan hasil yang didapatkan dari penelitian ini, maka dapat diambil kesimpulan sebagai berikut :

1. Pengolahan data penjualan yang dilakukan menghasilkan kelompok data yang paling tepat dijadikan strategi pemasaran berdasarkan data yang paling banyak diminati, sehingga pihak perusahaan dapat lebih mudah menentukan strategi pemasaran yang paling tepat.

2. Berdasarkan hasil pengolahan data dapat diketahui bahwa cluster 1 adalah kelompok dengan rata-rata penjualan paling tinggi dan paling tepat untuk dijadikan sebagai dasar dalam penentuan strategi pemasaran, cluster 2 adalah kelompok dengan rata-rata penjualan paling rendah, sehingga kurang tepat untuk dijadikan dasar dalam penentuan strategi penjualan, dan cluster 3 adalah klompok data yang berada di tengah-tengah dan masih bisa dipertimbangkan untuk dijadikan dasar penentuan strategi pemasaran.

\section{Saran}

Berikut ini adalah saran untuk pengembangan pada penelitian selanjutnya antara lain :

1. Untuk penelitian selanjutnya, bisa menambahkan atribut nilai proyek agar perusahaan dapat mengetahui data penjualan yang mana yang berpotensi meningkatkan omset pendapatan yang paling banyak.

2. Hasil dari penelitian dapat dijadikan sebagai salah satu referensi bagi pihak perusahaan dalam menentukan keputusan untuk menetapkan strategi pemasaran yang paling tepat.

\section{Referensi}

Alkhairi, P., \& Windarto, A. P. (2019). Penerapan K-Means Cluster pada Daerah Potensi Pertanian Karet Produktif di Sumatera Utara. Seminar Nasional Teknologi Komputer \& Sains, 
762-767.

Anisya. (2020). Data Mining Dalam Prediksi Pasokan Kelapa Sawit. RANGTEKNIKJOURNAL, 21(1), 1-9. https://doi.org/10.31869/rtj.v3i1.1332

Bahar, A., Pramono, B., \& Sagala, L. H. S. (2016). Penentuan strategi penjualan alat-alat tattoo di studio sonyxtattoo menggunakan metode. SemanTIK, 2(2), 75-86.

Basalamah, M. R., Athia, I., \& Jannah, M. (2018). Strategi Pemasaran Yang Tepat Guna Dalam Menghadapi Persaingan Pasar UMKM. Jurnal Ketahanan Pangan, 2(2), 190-197.

Marsono. (2019). Analisis Data Mining Pada Strategi Penjualan Produk PT Aquasolve Sanaria Dengan Menggunakan Metode K-Means Clustering. Teknologi Sistem Informasi Dan Sistem Komputer TGD, 2(1), 3241.

Metisen, B. M., \& Sari, H. L. (2015). Analisis clustering menggunakan metode $\mathrm{K}$ Means dalam pengelompokkan penjualan produk pada Swalayan Fadhila. Jurnal Media Infotama, 11(2), 110-118.

Mulaki, S. F., Setiyawati, N., \& Wijaya, A. F. (2018). Analisis Data Mahasiswa Menggunakan Algoritma K-Means Clustering sebagai Dasar Pelaksana Promosi. JBASE - Journal of Business and Audit Information Systems, 1(2), 30-39.

https://doi.org/10.30813/.v1i2.1259

Nduru, E. K., Buulolo, E., \& Pristiwanto, P. (2018). IMPLEMENTASI ALGORITMA K-Modes UNTUK MENENTUKAN STRATEGI MARKETING STMIK BUDI DARMA. KOMIK (Konferensi Nasional Teknologi Informasi Dan Komputer), 2(1),12-19.

https://doi.org/10.30865/komik.v2i1.90 3

Nurjoko, \& Darmawan, A. (2015). Penerapan Data Mining Menggunakan Association Rules untuk Mendukung Strategi Pemasaran Calon Mahasiswa baru (Studi Kasus IBI Darmajaya). TIM Darmajaya, 01(01), 17-32.

Wulandari, G. F. (2014). Segmantasi Pelanggan Menggunakan Algoritma KMeans Untuk Customer Relationship
Management ( CRM ) Pada Hijab Miulan. Industrial Marketing Management, pelanggan), 7 .
I(segmentasi 